\title{
Assessing the potential of bus rapid transit-led network restructuring for enhancing affordable access to employment - The case of Johannesburg's Corridors of Freedom
}

\author{
Christoffel Venter \\ Centre of Transport Development, Department of Civil Engineering, University of Pretoria, Pretoria 0002, South \\ Africa. +27 (0)12 4202184 christo.venter@up.ac.za
}

Keywords (up to 8):

Bus rapid transit, paratransit, network restructuring, accessibility, social exclusion, affordability.

Classification codes: 0180, 0170, 0210, 1320

\begin{abstract}
Bus rapid transit (BRT) systems are often implemented as a means toward achieving regulatory reform in the transport sector. This often involves simultaneous formalisation of informal paratransit operators, and restructuring of public transport networks into centrally planned trunk-feeder systems. Such interventions might radically affect passenger access and social inclusion in ways that are as yet poorly understood. The paper uses a new accessibility metric called access envelopes to examine the potential impacts of various restructuring options on passengers' wage earning potential at job opportunities across space. The Corridors of Freedom initiative of the City of Johannesburg is used as a case study of a BRT-led restructuring exercise with land use and transport components. The study finds that it is hard to improve on the accessibility provided by the current near-ubiquitous informal minibus-taxi network. The only way that BRT implementation can improve access and affordability in the short run is by offering a fully integrated trunk with feeder services. Should such feeder services be supplied via a hybrid formal-informal approach, an integrated and progressive fare policy is critical to maintaining affordable access for poor passengers. A laissez-fare approach where taxis are allowed to provide ad hoc feeder services without any fare integration, is likely to decrease affordable access.
\end{abstract}

\section{Introduction}

The achievement of socially inclusive development in cities is moving up the agenda in both industrialised and developing countries. Social inclusion encompasses human/social capabilities, financial resources, and spatial access to opportunities, and has a strong link to physical accessibility to key services and facilities (Lucas et al., 2007). The availability, quality, and cost of public transport play a key role in mediating social inclusion in cities, and have therefore received much attention in recent years. 
In many countries in Africa and Latin America, improving public transport means dealing with incumbent private sector operators providing informal paratransit services. Informal services are often associated with monopolistic pricing, low quality standards, poor road safety practices, and significant contributions to environmental and congestion externalities (Cervero and Golub, 2007). Efforts to improve standards are usually resisted by informal operators, at least partly because the benefits of transformation are not apparent. With the spread of bus rapid transit (BRT) around the world, planners have seen its implementation as an opportunity for leveraging regulatory reform, and in fact BRT has most often been implemented in parallel with such reform (Hook, 2005). BRT-led restructuring of existing services has been attempted in several cities, including Bogotá, Quito, Santiago, Lagos, and Johannesburg (Hook, 2005; Venter, 2013; Ferro and Behrens, 2015).

A review of these cases reveals considerable variation in the extent of network restructuring undertaken, and the pace of and manner in which paratransit operators are incorporated into revamped systems. Some informal operators are sidelined completely, while others are contracted in as providers of feeder services in a trunk-feeder model, or as sole operators of the entire BRT system. Scholars have examined the pros of cons of different approaches, with some arguing that with the introduction of formal-only trunk-and-feeder services, the benefits of flexibility and demand-responsiveness - the very properties that made paratransit effective at helping to include the poorest sectors of society - are lost (Ferro and Behrens, 2015). Ferro et al. (2013) have argued for a hybrid model, where informal and formal services can co-exist, at least as a transitional strategy until full integration becomes possible.

A key question that needs to be answered is how the various restructuring options affect passengers, especially from a social inclusion perspective. Passengers formerly dependent on paratransit services are often poor and marginalised, and vulnerable to disruptions in public transport coverage and price (Hook and Howe, 2005). This paper examines this question, by comparing the potential impacts on accessibility to employment, across various public transport network restructuring options centred around the introduction of a new BRT trunk service. To ground the analysis in reality we use as a case study the integrated land use-transport strategy adopted by the City of Johannesburg, South Africa, called Corridors of Freedom. We focus specifically on one corridor, the Louis Botha Avenue corridor, where a BRT trunk line linking a low-income community to the Johannesburg central business district is under construction.

The following section provides background on accessibility measurement and introduces the new accessibility metric, termed access envelopes, which addresses some of the shortcomings of previous methods. Then follows a description of the case study area and scenarios examined, and the findings. Lastly conclusions are drawn on the general implications of BRT-led network restructuring for the access enjoyed by low-income passengers.

\section{The access envelope technique as a measure of social impact}

\subsection{Accessibility measurement in the literature}


Accessibility is broadly defined as the ease of reaching desired destinations from a particular location, given a number of available opportunities and the difficulty (or impedance) of reaching them (Moseley, 1979). Opportunities may be measured in terms of employment positions or other key land uses such as shopping or educational facilities; travel impedance is usually measured in units of distance or time.

There has been a revival in scholarly interest in accessibility, both as a theoretical construct and as a spatial/transport evaluation tool. This is partly attributable to a conceptual shift among planners from focusing on mobility (i.e. the ability to travel) towards a focus on accessibility (i.e. the ability to participate in activities) (Cervero, 2005; Zegras, 2011). Accessibility is often distinctly linked to notions of equity and social justice, on the basis that accessibility deficits may lead to social exclusion and the denial of basic human rights (Martens, 2006; Preston and Raje, 2007). Lucas et al. (2007) make the link between accessibility and social sustainability of transport and land use strategies, focusing on accessibility to key services and facilities as a primary measure of social sustainability. In a review of the effectiveness of urban transport interventions in East Africa, Howe (2000: 12) notes that "it is the 'accessibility' that a transport system provides which is of fundamental importance to the extremely poor".

Attempts to apply the concept of accessibility in practice have generated a large amount of literature on accessibility measures and indicators. Useful overviews include Geurs and Ritsema van Eck (2001), Geurs and Van Wee (2004), and El-Geneidy and Levinson (2006). Geurs and Van Wee (2004) classified accessibility measures into four basic classes, namely infrastructure, location-based, person-based, and utility-based measures. Two approaches that fit under location-based measures - measures that reflect the aggregate accessibility from a specific location to spatially distributed activities - are of particular interest to the present work, namely gravity-type and threshold-type models.

First suggested by Hansen (1959), gravity-type measures sum all available opportunities in a study area, but weigh each according to a function of the travel impedance to reach them. Thus, opportunities located closer to the point of origin 'count' more than opportunities further away. An advantage of this class of measures is that it does not require the analyst to specify an arbitrary cut-off distance or travel time: all potential destinations are considered. But the choice of deterrence function - in essence a reflection of how quickly activities lose attractiveness as they become more difficult to reach - is not straightforward. The complexity of gravity indices also makes them more difficult to interpret by decision-makers. Recent applications of gravity-type models to non-auto modes include lacono et al. (2008) and Bocarejo and Oviedo (2012).

Threshold-type measures, by contrast, specify a cut-off value and only count the number of opportunities that are located within that boundary. Examples include catchment or contour analyses, which count the number of job opportunities a person can reach from a given origin location within a specified commute time. An expansion of this metric indicates an improvement in accessibility over time, due to for instance a transportation improvement or positive job growth in the area (El-Geneidy and Levinson, 2007).

A common shortcoming in the way accessibility measures of both types are applied is the incomplete representation of travel impedance. Travel disutility is most commonly measured using travel distance and time. While this might be tenable in the case of car-based 
accessibility, where travel costs are largely proportional to travel distance or time, the same is not true for public transport. Fares can vary significantly across operators in an area, and the use of flat fares, transfer penalties or staged-based fares can mean that actual fare structures for a journey are far from linear.

It is critically important that affordability be recognised as a key dimension of access. Affordability is a key constraint to mobility among the urban poor, many of whom spend 20 to $30 \%$ of their household income on travel (Howe, 2000; Diaz Olvera et al., 2008; Venter, 2011). It makes no sense to examine access or time-based accessibility while disregarding the fact that many people simply cannot afford to travel to a destination.

\subsection{Accessibility and spatial equity of public transport systems}

A number of recent studies have applied accessibility techniques to study the spatial equity implications of public transport interventions. Fan et al. (2012) calculated the number of jobs (per wage category) that can be reached within a 30-minute travel time from each residential block in the Minneapolis-Saint Paul area, both before and after the introduction of a new light-rail line. Comparing these figures for workers of different wage categories, they found that being located close to improved transit leads to large, statistically significant gains in accessibility for low-wage workers, and a positive equity impact. Tiwari and Jain (2012) also applied a contour-type metric to measure the accessibility benefits of the Delhi BRT, by calculating the number of destinations (by type) that are within reach of different types of road users, and the number and type of users for whom this metric has increased (compared to the pre-BRT situation).

Delmelle and Casas (2012) used a similar approach to measure the extent to which the Masivo Integrado de Occidente (MIO) BRT system of Santiago de Cali (Colombia) enhanced access to activities for different income groups. Access to the BRT was measured by counting the population (by socio-economic stratum) living within certain walking time bands of BRT stations. Access via the BRT was measured using a gravity-type index that incorporated both door-to-door travel time, and the locations of activities. They showed that accessibility enhancements attributable to MIO are skewed in favour of middle and uppermiddle strata more centrally located in the city.

Jaramillo et al. (2012) adapted a technique originally developed in Australia (Currie, 2004) to measure the extent of transport deprivation of a community, taking its locational and demographic characteristics as well as its access to public transport services into account. Applying this measure in Cali, they found that the BRT fails to improve access for many of the city's poor households located in peripheral districts.

In one of the few attempts to date to incorporate affordability in access measurement, Bocarejo and Oviedo (2012) combined travel time and cost into a generalised cost function in a gravity-type index. Applying the measure to Bogotá's TransMilenio Phase 3 BRT system, the authors found that accessibility losses from fare increases would be offset by increases in speed. However it is not clear that travel time and cost are actually traded off in users' perception of accessibility to job destinations.

\subsection{Access envelopes}


The accessibility measure used in this study, access envelopes, was developed in South Africa as a tool for exploring the spatial implications of combined housing and transport interventions in terms of access to the space economy afforded to poverty populations (Venter and Cross, 2014). It addresses some of the shortcomings mentioned above. The key output of the measure is what is termed the net wage after commute (NWAC), which represents the earning potential for workers living in a particular location, taking into account the spatial distribution of jobs; the cost/fare of travelling to those jobs by all available public transport modes and walking; the impact on daily earnings of excessively long travel times; and the actual wages per sector paid at each location. The measure is explicitly oriented towards earnings and costs, reflecting the importance of financial exclusion as a key aspect of (in)accessibility.

Input data include GIS layers on the distribution of job opportunities (taking care to include only jobs that match the typical resident's skills and education profile in the area); wage levels; public transport network and fare data; and street networks from which to estimate walking distances. The data requirements are somewhat onerous, but generally available from official sources and emerging open source maps and databases, even in developing countries.

A specific origin area is chosen. An NWAC value is calculated from that origin to all potential job location zones within the study area, which is equal to the average daily wage earnable at the zone minus the daily cost of commuting to and from the zone. By subtracting commute cost, the measure is sensitive to the fares charged by public transport operators and to operational policies such as forced transfers between services (which usually require payment of a second fare).

The NWAC value is calculated for a specific mode, or across different mode combinations (including walking as main or feeder mode), using the following formula:

$$
N W A C_{i, j}=\max _{\begin{array}{c}
\text { all mode } \\
\text { combinations } \\
m
\end{array}}\left({\overline{\text { Income }_{j}}}-\text { Fare }_{i, j, m}-\delta \cdot\left[\frac{\text { Time }_{i, j, m}-T}{H} * \overline{\text { Income }}_{j}\right]\right)
$$

Where $N W A C_{i, j}=$ Net wage after commute at job location $j$, from origin $i$

$$
\begin{aligned}
& {\overline{\text { Income }_{j}}}_{j}=\text { Average daily wage earned at location } j \\
& \text { Fare }_{i, j, m}=\text { Daily public transport fare between } i \text { and } j \text {, via mode combination } m \\
& \text { Time }_{i, j, m}=\text { Travel time between } i \text { and } j \text { via mode combination } m \text { (return trip) } \\
& \mathrm{T}=\text { Threshold daily travel time (assumed } 120 \text { minutes) } \\
& \mathrm{H}=\text { Length of average working day (assumed } 8 \text { hours or } 480 \text { minutes) } \\
& \delta=1 \text { if } \text { Time }_{i, j, m}>\mathrm{T} ; 0 \text { otherwise }
\end{aligned}
$$

The last term in the equation is referred to as the excess travel time penalty, as it captures the reduction in daily income due to excessively long travel times. The measure does not include travel time impedance using some continuous mathematical function, as is common in gravity-type indices. Instead, only excessively long travel times are accounted for in terms 
of the extent to which they might actually reduce the take-home earnings at the specific location.

This approach draws on several theoretical and empirical arguments. Firstly, the concept of the travel-time budget, by now well-established in the literature, suggests that people habitually plan for a fixed total amount of travel in their day (e.g. Zahavi, 1974; Levinson and Kumar, 1994). It is argued that commuters have a 'reasonable travel time budget' or 'acceptable travel time' (Milakis et al., 2015) that they can absorb with little or no cost consequences. For instance, Welch and Williams (1997) found that marginal costs tend to be low for the first 20 to 40 daily minutes of personal travel, but become large if travel time exceeds about 90 minutes. Excessive travel times might force commuters to compensate in ways that might decrease their net wage, for instance by working fewer hours per day, or by incurring additional health or social costs (Litman, 2009).

Secondly, several researchers have raised questions about the manner in which travel time savings are valued, suggesting it may not have a solid or straightforward behavioural basis (e.g Mokhtarian, 2005; O'Fallon and Wallis, 2012). Low-income commuters have been found to have very low values of time, partly because their ability to pay for travel time savings is severely budget constrained (Litman, 2009). The NWAC measure avoids the necessity of valuing travel time, beyond its direct effect on income.

A travel-time threshold of 1 hour per direction (2 hours of travel per day) is used, reflecting the relatively long travel times of South African commuters.

In the present case destinations are represented using a fine hexagonal grid roughly $130 \mathrm{~m}$ in diameter. NWAC results can be plotted for all destinations, producing a visual representation of the spatial variation in accessibility. Two summary measures are also calculated to help compare the overall performance of various scenarios, namely:

- The total number of job opportunities that can be reached with an NWAC value larger than a given minimum. This reflects the size of the pool of jobs within reasonable accessibility limits - in effect the breadth of access benefits - and the higher this indicator, the more likely a job seeker would be to find a suitable job, all else being equal.

- The average NWAC value for the closest 200000 jobs. This indicator reflects the distribution of wages and travel times and costs in the surrounding area, while controlling for the number of jobs - in effect the depth of access benefits. Scenarios with low wages or high transport costs would score lower on this measure.

\section{Case study: Johannesburg's Corridors of Freedom initiative}

\subsection{Background}

As a case study the paper takes the City of Johannesburg's 'Corridors of Freedom' initiative, which is an attempt at addressing the Apartheid-legacy spatial exclusion problems typical of South African cities, through integrated land use and transport improvements. The strategy is significant from both a national and an international perspective, as it provides an opportunity to test the effectiveness of some of the New Urbanist inspired policy that has been 
developed as a way of improving livelihoods of poor, marginalised households in developing cities.

The corridor-based strategy selects corridors linking economic nodes with higher density residential developments, and with significant potential for urban regeneration and densification along the corridor. Transit Oriented Development (TOD) is encouraged within key nodes and historical township and marginalised areas of the city, to increase economic activities outside the Central Business District (CBD). Investment in public infrastructure is used to promote walkability and quality of life in the corridor. Public transport investment is seen as the backbone of the strategy to improve mobility along the corridor (CoJ, 2013).

Bus Rapid Transit has been selected as the preferred mode of public transport upgrading in Johannesburg. Starting in 2009, the City has been implementing full service BRT corridors along two routes connecting Soweto to the CBD, integrated with feeder bus services and cycling and pedestrian infrastructure (Figure 1). These two corridors have also been chosen as the first Corridors of Freedom.

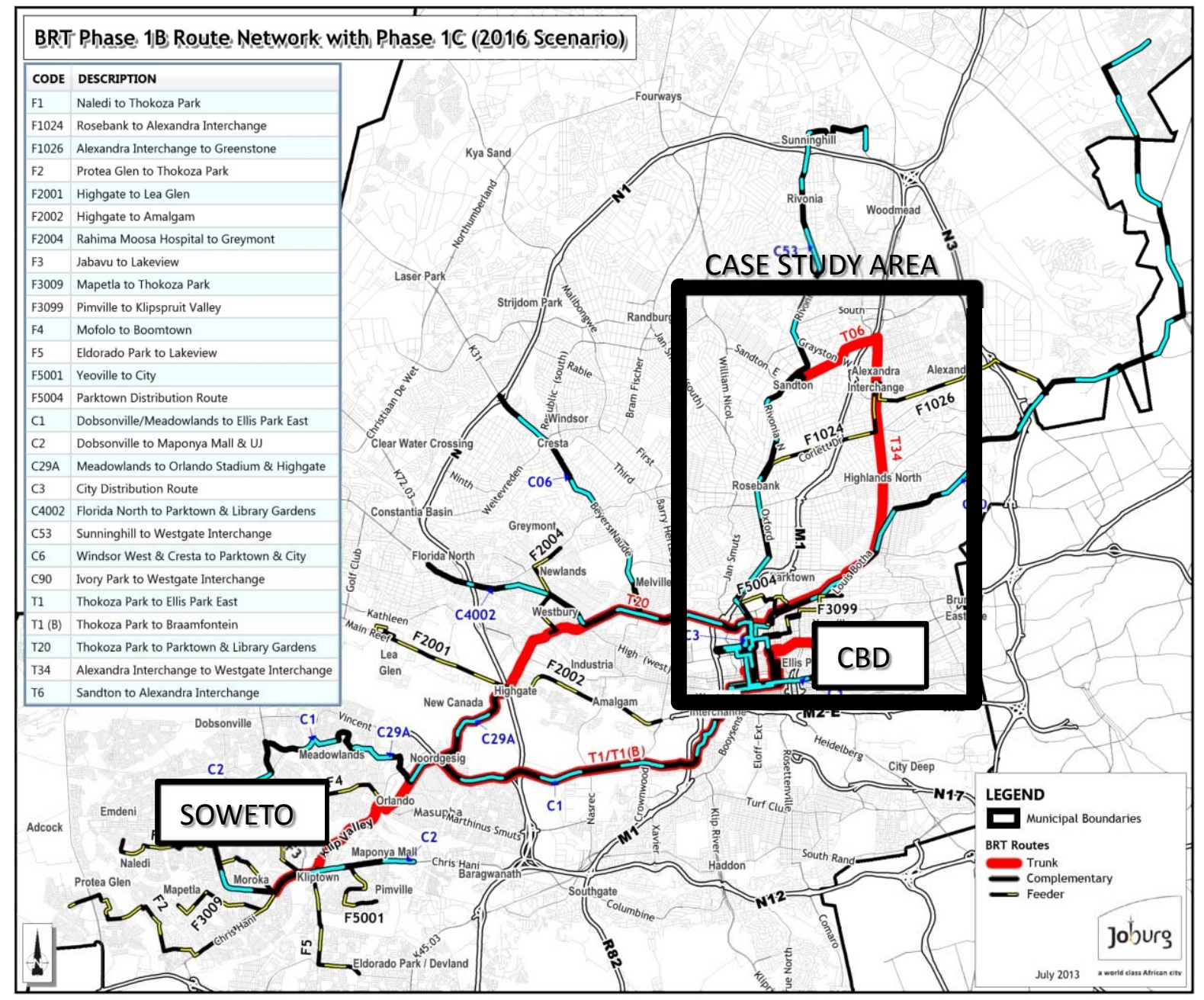

Figure 1. City of Johannesburg and Rea Vaya BRT network. (Adapted from CoJ (2013)). 
A key aspect of the BRT programme is that it is being used as a vehicle for transforming and formalising the informal minibus-taxi industry. Existing minibus operators are not allowed to compete with BRT on the same routes; instead, owners and drivers are co-opted into becoming stakeholders in the operating company providing the BRT service. The objectives are to reduce the putative over-supply of minibus services while assisting in professionalising current operators (McCaul and Ntuli, 2011).

The present study focuses on the third Corridor of Freedom, extending northwards from the CBD along Louis Botha Avenue towards the low-income residential area of Alexandra (Alex), and then westwards to the commercial node of Sandton (Figure 1). Up to 60\% of people living in Alexandra are unemployed, and $20 \%$ earn less than $\mathrm{R} 1000^{1}$ per month. Minibustaxis provide the only public transport in the area: about $75 \%$ of work trips from Alex are currently made by minibus-taxi, about $20 \%$ by car, and $5 \%$ by walking. An explicit objective of the plan is to promote affordable public transport enabling poor commuters to access a range of urban opportunities within the broader urban space (Seftel, 2014).

The BRT trunk route, currently under construction, will include $16 \mathrm{~km}$ of dedicated median buslanes, 13 new stations, and 5 integrated feeder routes. Projected ridership of around $11,000 \mathrm{pass} / \mathrm{hr} /$ direction is expected on the CBD-Alex section, and about 8,500 on the AlexSandton section (CoJ, 2013).
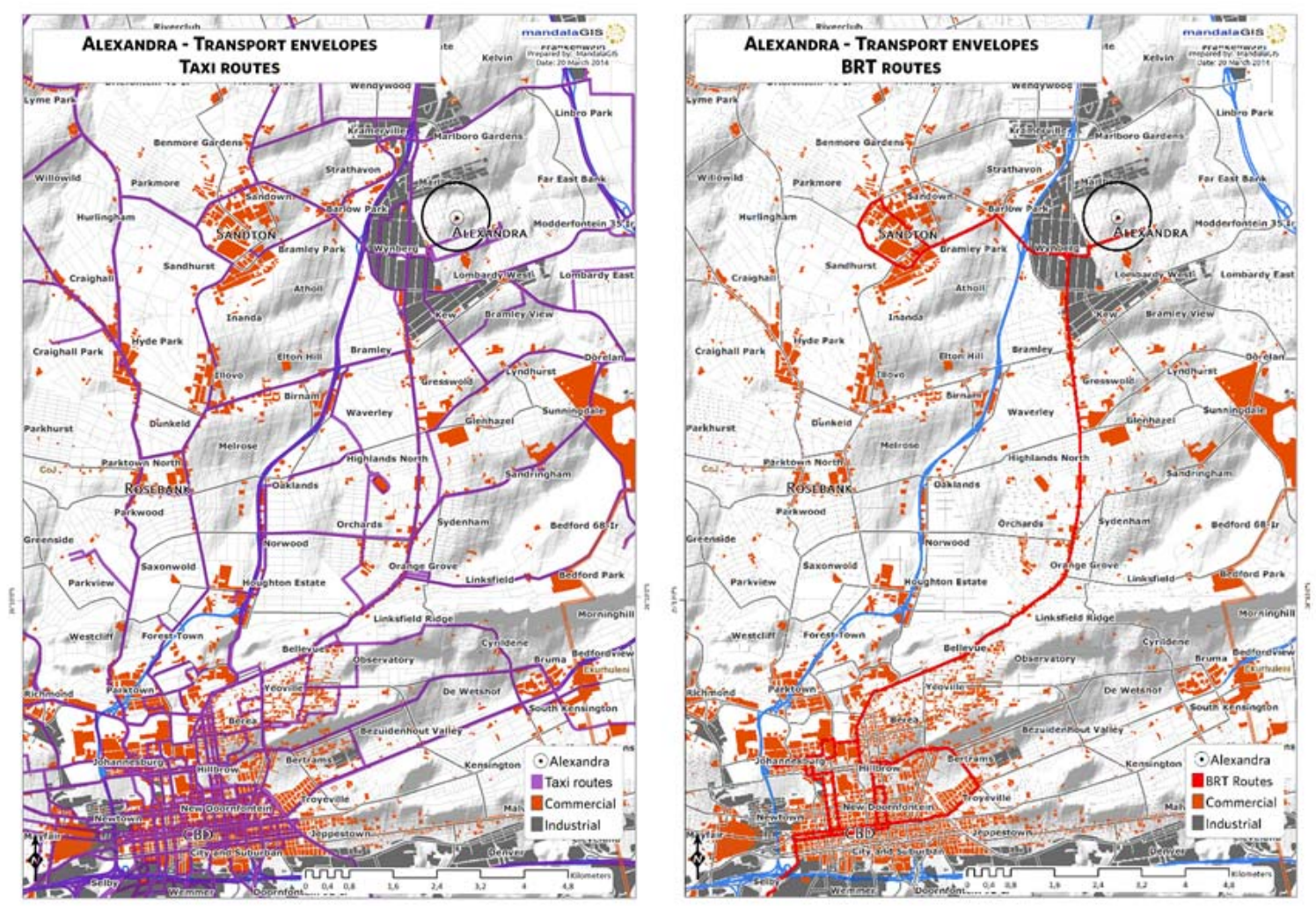

Figure 2. (a) Current minibus-taxi routes and (b) planned BRT trunk routes

${ }^{1}$ At current exchange rates, 1000 SA Rands is equivalent to about 68 US Dollars. 
Current taxi routes and the planned BRT trunk route are shown in Figure 2. Comparing the relatively dense taxi route network with the single BRT line, the question can be asked what the accessibility implications would be of replacing taxi services with a BRT trunk. The project also offers the opportunity of examining the access implications of various feeder strategies, either of 'hybrid' formal-informal services, or of an integrated formal-only network. The access envelope methodology offers a way of exploring these questions in more detail.

\subsection{Scenarios}

Six scenarios are constructed for analysis. All access envelope calculations consider Alexandra as the origin area, thus reflecting access and affordability patterns from the point of view of Alex residents.

\section{Scenario 1: Informal minibus-taxi only (baseline)}

This scenario reflects the status quo, with area-wide taxi routes as shown in Figure 2(a).

\section{Scenario 2: BRT trunk only, with baseline pricing}

All taxi routes are replaced by the BRT trunk line shown in Figure 2(b). No feeder services are provided, so passengers walk between the BRT trunk and job zones. In order to study the accessibility impacts of BRT implementation in isolation from the affordability question, it is assumed that the BRT trunk would adopt a staged-based fare structure similar to current taxi fares.

\section{Scenario 3: BRT trunk only, with progressive pricing}

The same as scenario 2, but the fare structure of the BRT trunk is adapted to be similar to the distance-based fare structure currently used by Rea Vaya. The maximum one-way fare to the CBD is R9.00, a $28 \%$ saving compared to the baseline (taxi) fare. Data from the City of Johannesburg show that minibus-taxi operators charge stage-based fares that can amount to $\mathrm{R} 25$ for a return trip to the $\mathrm{CBD}^{2}$, making travel from Alexandra relatively expensive.

\section{Scenario 4: BRT trunk with taxi feeders}

The BRT trunk is complemented by taxi feeder routes at all stations, but no line-haul taxi routes are allowed. Passengers are forced to transfer to taxis, or can walk to their final destination if a lower NWAC value would result (i.e. it is assumed that passengers maximise their net income minus commute costs). The BRT trunk portion of the trip is priced progressively (see Scenario 3), but for the taxi portion an additional fare equal to the typical short-distance fare of R9.50 is charged.

\section{Scenario 5: BRT trunk and original taxi linehaul}

In this scenario the effect of simply superimposing the BRT trunk onto the existing taxi network is tested. The NWAC value for each destination is based on the mode (BRT, taxi or walking) that would maximise net wage. Progressive pricing is assumed for the BRT, and existing pricing for taxis.

\section{Scenario 6: BRT trunk and integrated feeders}

\footnotetext{
${ }^{2}$ A daily fare of R25 amounts to about $20 \%$ of the average daily wage amongst low-income earners in Johannesburg.
} 
No taxi services are allowed. Feeder services are provided to the BRT trunk connecting at three BRT stations, as suggested by the CoJ. Both the BRT trunk and the BRT feeder services are priced according to the progressive fare structure; the feeder trips add a maximum of R3.00 to the fare. This scenario has fewer feeder routes (thus potentially lower area coverage) than Scenario 4, but also lower door-to-door travel costs.

In all scenarios, 2013 employment and income data were obtained from the Gauteng Department of Transport's transport model, combined with wage information from earlier surveys. The calculations were implemented using ArcGIS software.

\section{Results and discussion}

Aggregate results from the access envelope analyses are shown in Table 1. For the first aggregate measure - a count of the total relevant job opportunities with an NWAC level exceeding a given threshold - a threshold value of R104 was chosen. This corresponds to the median wage less $20 \%$ for transport costs ${ }^{3}$.

Table 1. Access envelopes aggregate results: Johannesburg's Louis Botha Avenue Corridor of Freedom scenarios

\begin{tabular}{|c|c|c|c|c|c|}
\hline Scenario & Description & $\begin{array}{c}\text { Total job } \\
\text { opportunities } \\
\text { with NWAC } \\
\text { larger than } \\
\text { R104 }\end{array}$ & $\begin{array}{c}\% \\
\text { change } \\
\text { from } \\
\text { baseline }\end{array}$ & $\begin{array}{l}\text { Average } \\
\text { NWAC } \\
\text { value for } \\
\text { closest } \\
200 k \\
\text { jobs }\end{array}$ & $\begin{array}{c}\% \\
\text { change } \\
\text { from } \\
\text { baseline }\end{array}$ \\
\hline 1 & $\begin{array}{l}\text { Informal minibus-taxi } \\
\text { only (baseline) }\end{array}$ & 505,630 & - & R114.59 & - \\
\hline 2 & $\begin{array}{l}\text { BRT trunk only, with } \\
\text { baseline pricing }\end{array}$ & 371,734 & $-26.5 \%$ & R113.85 & $-0.6 \%$ \\
\hline 3 & $\begin{array}{l}\text { BRT trunk only, with } \\
\text { progressive pricing }\end{array}$ & 422,742 & $-16.4 \%$ & R120.82 & $+5.4 \%$ \\
\hline 4 & $\begin{array}{l}\text { BRT trunk with taxi } \\
\text { feeders }\end{array}$ & 447,954 & $-11.4 \%$ & R109.55 & $-4.4 \%$ \\
\hline 5 & $\begin{array}{l}\text { BRT trunk and original } \\
\text { taxi linehaul }\end{array}$ & 527,874 & $+4.4 \%$ & R120.82 & $+5.4 \%$ \\
\hline
\end{tabular}

\footnotetext{
${ }^{3}$ While the South African target is that commuters should spend less than $10 \%$ of their income on public transport, the actual figure for low-income public transport users is $21 \%$ (Venter, 2011). We benchmark our indicator closer to the actual figure.
} 


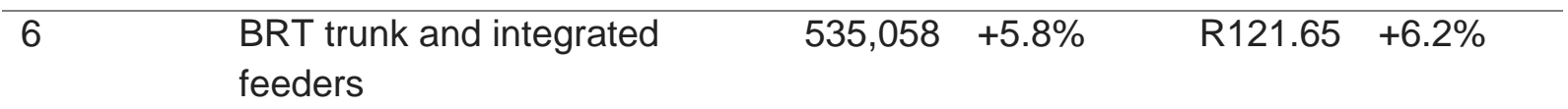

\subsection{Effect of replacing informal minibus with trunk-only BRT service}

A comparison of scenarios 1 and 2 shows the impact of entirely replacing existing ubiquitous minibus-taxi services with a single BRT trunk line, while keeping fares at current levels. This has a disastrous effect on job access, as shown by the $26 \%$ drop in the number of jobs with NWAC values above the median. The reason is clear when looking at the excess travel time penalty maps shown in Figure 3 . The lightest shading on each map indicates the areas that are reachable with a zero penalty - i.e. within a one-way travel time of 60 minutes from Alexandra. With the current ubiquitous taxi routes almost the entire study area is reachable; under the trunk-only BRT scenario, the area narrows significantly to a band within walking distance around the trunk and the origin area. The scenario is not realistic as it drastically shrinks the public transport coverage area.
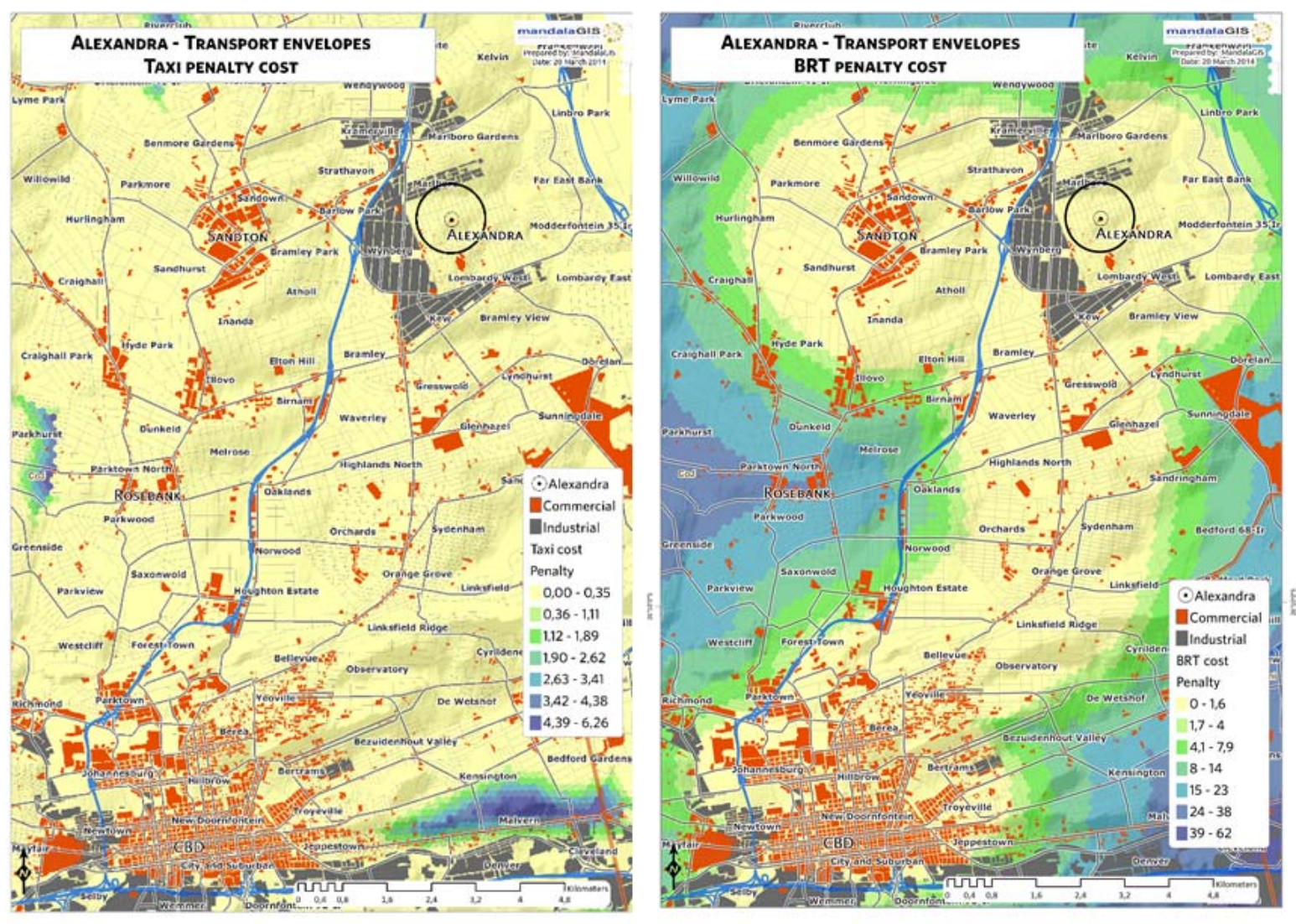

Figure 3. Excess travel time penalty for (a) taxi (scenario 1) and (b) BRT trunk (scenario 2)

\subsection{Effect of BRT fare strategy}


Scenarios 2 and 3 are similar (BRT trunk only, no taxi), except that the latter employs a progressive fare strategy that lowers trunk travel costs below existing levels. Table 1 shows that while fare control does not quite offset the accessibility loss due to the removal of taxi services (the number of jobs with above-median NWAC values is still $16 \%$ below the baseline), it has a major mitigating effect. While the number of high-earning jobs that can be reached is still lower than the baseline, those jobs deliver a higher net wage than currently. What this scenario suggests is that the fare strategy is a very important component of the potential poverty-reduction benefits that can be obtained with a BRT system.

\subsection{Effect of superimposing BRT trunk onto existing taxi services}

Instead of removing all informal operators, they might be left as is, and the BRT trunk line simply superimposed on the existing service (scenario 5). As can be expected, this raises overall accessibility as many passengers now have a choice between existing taxi, BRT trunk, and walking all the way to their destinations. The accessibility and net wage gain is about 4 to $5 \%$ above the baseline situation.

Plots of the NWAC surface provide insight into the spatial distribution of incremental accessibility gains under this strategy. Figure 4(b) shows NWAC improvements to be concentrated around the BRT corridor, and especially at its endpoints around the major employment nodes of Sandton and the CBD. In the CBD the BRT trunk links up with the rest of the Rea Vaya network, extending accessibility improvements over a wide area. These improvements are mainly due to the reduction in fare for longer-distance trips offered by the BRT; taxi fares tend to be more distance-dependent due to their operating cost structure. Thus the effect of the BRT trunk would be to enhance the accessibility of existing areas of high employment. Substantial opportunities exist for densification along the corridor, in order to take advantage of the access enhancement achieved by the BRT trunk. 

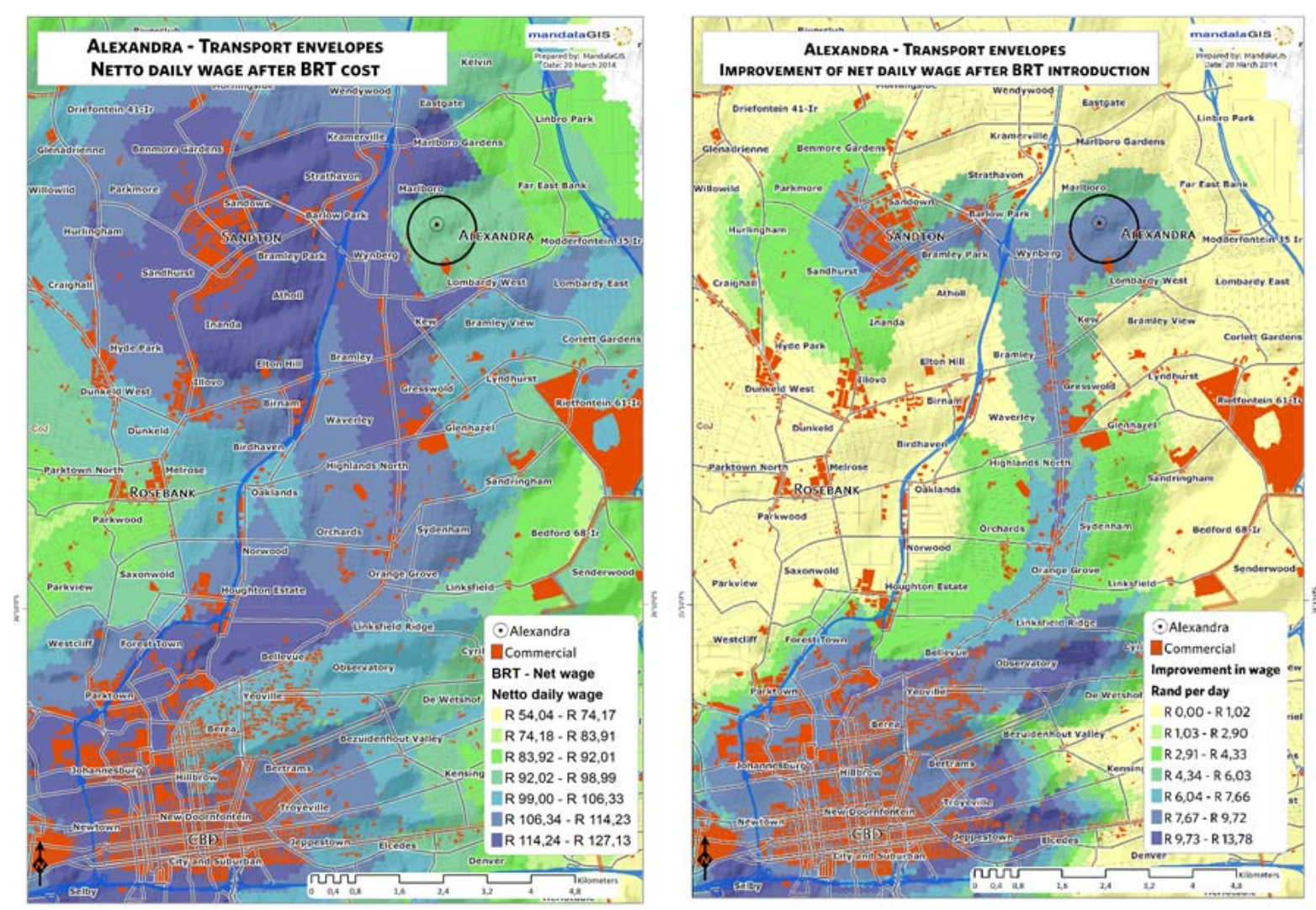

Figure 4. (a) NWAC results for scenario 3 (BRT trunk with progressive pricing); (b) Improvement in NWAC values due to scenario 5 (BRT trunk plus existing taxi)

\subsection{Effect of feeder strategy}

Scenarios 4, 5 and 6 represent three different ways of extending public transport coverage beyond the BRT trunk: by limiting taxis to providing ad-hoc feeder services (not under the control of the BRT authority) as long as they do not compete with the BRT trunk; by allowing the taxis to operate a parallel network; and by offering formal feeder services integrated with the BRT. The first two options represent two potential approaches towards 'hybrid' operations, with a mix of formal and informal operations.

Of the three options, the ad-hoc taxi feeder option performs worst in terms of accessibility. It reduces access to above-median jobs by $11 \%$, and take-home earnings by $4 \%$. The forced transfer adds a small amount of travel time to some passengers' journeys, but this effect is not significant due to the high frequency of taxi operations. A far more important factor is the separate fare systems of the BRT and taxi feeder, imposing a significant financial penalty on transferring passengers.

Scenario 6 does not impose this additional flagdrop on transfers, but assumes that formal BRT feeder routes are charged only according to the extra distance travelled, in line with current Rea Vaya policy. Despite the reduction in feeder routes - only 3 feeder routes are considered as compared to many taxi routes - the overall performance of this scenario is much better than the previous case. In fact, scenario 6 delivers the highest accessibility gains of all scenarios, increasing access to above-median jobs as well as take-home pay by $6 \%$. This mirrors findings from Bogotá, Colombia, where total daily savings in the order of 
8\%-12\% was reported for low income Transmilenio Phase 1 passengers who would have paid two fares on the traditional informal system (Hidalgo and Yepes, 2005).

\section{Conclusions}

It is hard to improve on the accessibility offered by a near-ubiquitous informal paratransit network. Most of the BRT-led scenarios investigated in the study lead to reductions or very modest improvements in affordable access to job opportunities. The extent of the impacts depends on the approach adopted towards the informal sector. At one extreme, eradicating minibus-taxis altogether and replacing them with a single trunk BRT service is likely to have disastrous consequences for job access and employment, as it reduces public transport coverage significantly. This scenario should warn against attempts at wholesale eradication of informal services without replacing them with suitable alternatives.

At the other extreme, the BRT trunk could be superimposed on the existing informal network without changing it at all. This scenario might emerge where public authorities lack the ability to enforce route restructuring or regulatory reform of paratransit operations. Theoretically this approach can only improve access, as passengers gain more travel options. The present analysis suggests access improvements of about $4-5 \%$ are possible, although this is due to the affordability gains offered by the progressive fare policy of the BRT system, rather than increased speed and connectivity. If congestion was more severe, travel time benefits might also accrue after introduction of the BRT trunk. However this scenario would be difficult to sustain in practice: by allowing informal paratransit services to compete directly with the BRT trunk corridor, BRT ridership and revenue would be depressed, making it less likely that a progressive fare policy could be sustained over the long term.

In reality, some middle way would need to be found to balance access and affordability. Two feeder strategies were tested: allowing taxis to offer feeder services in an ad-hoc manner without formal coordination with the BRT; or offering feeder services formally integrated with the BRT trunk. The latter is found to be the better option, mostly due to the opportunities it offers for integrated ticketing. Ad hoc taxi feeders charge a second flagdrop fare when passengers transfer to/from the BRT trunk, increasing travel costs significantly above the baseline and leading to an $11 \%$ loss in job access. Integrated trunk and feeder services, charged according to a distance-based structure that avoids transfer penalties, improves overall accessibility and the net earnings potential of commuters by about $6 \%$ above the baseline. This scenario might still have elements of a 'hybrid' solution that doesn't require complete formalisation of paratransit operators offering feeder services, but a key condition is that authorities must be able to exercise effective control over paratransit fares. Without this control, it is likely that accessibility and affordability will be worse than without the BRT-led restructuring.

This point illustrates the importance of adopting progressive fare strategies for improving affordable access to job opportunities. The research clearly shows that lower public transport pricing - made possible either through improving operational efficiencies or through direct subsidisation - is amongst the most significant tools that can be used to promote social inclusion among the urban poor. How this might be effectively achieved, without either 
overburdening public coffers or losing the cooperation of private operators, is a topic in urgent need of further research.

However, even the best-case scenario above achieves a relatively modest improvement, especially when compared to the financial and political cost involved in constructing the BRT system, subsidising fares, and transforming an existing informal industry. The accessibility analysis highlights where land use change might be directed if more benefits are to be realised. In the present case, access benefits are limited by the low-density nature of the corridor stretching between higher density nodal developments at its endpoints. The corridor itself is relatively devoid of significant job centres. The BRT investment creates a new 'swath of high access' within walking distance of the trunk route. Unless significant new employment generation, coupled with higher density housing and public services, are progressively attracted to this swath, there is a danger that the potential benefits of BRT-led spatial transformation will not be realised. In this sense the integrated transport and land use vision articulated by the Corridors of Freedom strategy might be exactly the kind of intervention that is needed.

\section{Acknowledgements}

The author gratefully acknowledges the contributions of Catherine Cross from the Human Sciences Research Council, who helped develop the access envelope methodology, and Willem Badenhorst from MandalaGIS, who helped with GIS analysis and preparation of maps. The work reported in this article was partly sponsored by the South African Department of Science and Technology through the StepSA project.

\section{References}

Bocarejo, J.P.S. and Oviedo, D.R.H. 2012. Transport accessibility and social inequities: A tool for identification of mobility needs and evaluation of transport investments. Journal of Transport Geography 24, 142-154.

Cervero, R. 2005. Accessible cities and regions: A framework for sustainable transport and urbanism in the 21st century. Working Paper UCB-ITS-VWP-2005-3, University of California. $<$ http://repositories.cdlib.org/its/future urban transport/vwp-2005-3> [Accessed: 30 July 2007].

Cervero, R. and Golub, A. 2007. Informal transport: A global perspective. Transport Policy 14(6), 445-457.

City of Johannesburg. 2013. Strategic integrated transport plan framework for the City of Johannesburg. Johannesburg, South Africa.

Currie, G., 2004. Gap analysis of public transport needs: measuring spatial distribution of public transport needs and identifying gaps in the quality of public transport provision. Transportation Research Record No. 1895, 137-146. 
Delmelle, E.C. and Casas, I. 2012. Evaluating the spatial equity of bus rapid transit-based accessibility patterns in a developing country: The case of Cali, Colombia. Transport Policy 20(2), 36-46.

Diaz Olvera, L., Plat, D. and Pochet, P. 2008. Household transport expenditure in subSaharan African cities: Measurement and analysis. Journal of Transport Geography, 16(1), 1-13.

El-Geneidy, A.M. \& Levinson, D.M. 2006. Access to destinations: Development of accessibility measures. Report 1 in the series: Access to Destinations Study, Report 200616. University of Minnesota: Minnesota. <http://www.Irrb.org/PDF/200616.pdf> [Accessed: 18 October 2006].

El-Geneidy, A. \& Levinson, D. 2007. Mapping accessibility over time. Journal of Maps, 3(1), 76-87.

Fan, Y., Guthrie, A., and Levinson, D. M. 2012. Impact of light rail implementation on labor market accessibility: A transportation equity perspective. Journal of Transport and Land Use, 5(3), 28-39.

Ferro, P.S., Behrens, R., and Wilkinson, P. 2013. Hybrid urban transport systems in developing countries: portents and prospects. Research in Transportation Economics 39(1), 121-132.

Ferro, P. S., and Behrens, R. 2015. From direct to trunk-and-feeder public transport services in the Urban South: Territorial implications. Journal of Transport and Land Use, 8(1), 123136.

Geurs, K.T. and Ritsema Van Eck, J.R. 2001. Accessibility measures: Review and applications. National Institute of Public Health and the Environment, Urban Research Centre, Utrecht University, Utrecht.

<http://www.rivm.nl/bibliotheek/rapporten/408505006.pdf> [Accessed: 1 July 2013].

Geurs, K.T. and van Wee, B. 2004. Accessibility evaluation of land-use and transport strategies: review and research directions. Journal of Transport Geography 12, pp. 127-140.

Hansen, W. 1959. How accessibility shapes land use. Journal of the American Institute of Planners, 25, pp. 73-76.

Hidalgo, D. and Yepes, T. 2005. Are Bus Rapid Transit Systems Effective in Poverty Reduction? Experience of Bogotá's TransMilenio and Lessons for Other Cities. Paper presented at Transportation Research Board's Annual Meeting, Washington, D.C.

Hook, W., 2005. Institutional and Regulatory Options for Bus Rapid Transit in Developing Countries: Lessons from International Experience. Presented at Annual Meeting of Transportation Research Board, Washington, D.C.

Hook, W. and Howe, J. 2005. Transport and the Millennium Development Goals. Background Paper to the Task Force on Slum Dwellers of the Millennium Project.

Howe, J. 2000. Poverty and urban transport in East Africa: Review of research and Dutch donor experience. Report prepared for the World Bank. International Institute for Infrastructural, Hydraulic and Environmental Engineering. 
lacono, M., Krizek, K. and El-Geneidy, A. 2008. Access to destinations: How close is close enough? Estimating accurate distance decay functions for multiple modes and different purposes. Report no. Mn/DOT 2008-11, University of Minnesota: Minnesota. Available from: <http://www.Irrb.org/PDF/200811.pdf> [Accessed: 18 August 2008].

Jaramillo, C., Lizárraga, C. and Grindlay, A.L. 2012. Spatial disparity in transport social needs and public transport provision in Santiago de Cali (Colombia). Journal of Transport Geography, 24, pp. 340-357.

Levinson, D.M. and Kumar, A. 1994. The Rational Locator. Why travel times have remained stable. Journal of the American Planning Association, 60(3), 319-332.

Litman, T. 2009. Transportation Cost and Benefit Analysis: Techniques, Estimates and Implications - Travel Time Costs. Victoria Transport Policy Institute.

(www.vtpi.org/tca/tca0502.pdf).

Lucas, K., Marsden, G., Brooks, M., and Kimble, M. 2007. Assessment of capabilities for examining long-term social sustainability of transport and land use strategies. Transportation Research Record No. 2013.

Martens, K. 2006. Basing transport planning on principles of social justice. Berkeley Planning Journal, 19(1), 1-17.

McCaul, C., and Ntuli, S. 2011. Negotiating the deal to enable the first Rea Vaya bus operating company: Agreements, Experience and Lessons. In Proceedings: $30^{\text {th }}$ Southern African transport conference, Pretoria, South Africa.

Milakis, D., Cervero, R., Van Wee, B., and Maat, K. 2015. Do people consider an acceptable travel time? Evidence from Berkeley, CA. Journal of Transport Geography, 44, 76-86.

Mokhtarian, P.L. (Editor) 2005. Special Issue: The Positive Utility of Travel. Transportation Research Part A, Vol. 39A(2-3)

Moseley, M. J. 1979. Accessibility: The Rural Challenge. London: Methuen.

O'Fallon, C. and Wallis, I. 2012. A Wider Look at How Travellers Value the Quality and Quantity of Travel Time, New Zealand Transport Agency Research Report 469.

Preston, J., and Rajé, F. 2007. Accessibility, mobility and transport-related social exclusion. Journal of Transport Geography 15(3), 151-160.

Seftel, L, 2014. How does mobility support inclusivity and efficiency in the city? City of Johannesburg Case Study: Louis Botha Corridor. Paper presented at Spatial Transformation of Cities Conference, Johannesburg, 4 - 6 March 2014. Available from:

<http://www.sacities.net/joburg_spatial_transformation/Downloads/Louis\%20Botha\%20Corrid or\%20SACN\%20conference_Isptx.pdf > [Accessed: 9 May 2014].

Tiwari, G., and Jain, D. 2012. Accessibility and safety indicators for all road users: Case study Delhi BRT. Journal of Transport Geography 22(1), 87-95.

Venter, C. 2011. Transport expenditure and affordability: The cost of being mobile. Development Southern Africa, 28(1), 121-140. 
Venter, C. 2013. The lurch towards formalisation: Lessons from the implementation of BRT in Johannesburg, South Africa. Research in Transportation Economics 39(1), 114-120.

Venter, C., and Cross, C. 2014. Access envelopes: A new accessibility mapping technique for transport and settlement planning. Town and Regional Planning (64), 43-52.

Welch, M. and Williams, H. 1997. Sensitivity of Transport Investment Benefits to the Evaluation of Small Travel-Time Savings. Journal of Transport Economics and Policy, 31(3), Sept., 231-254.

Zahavi, Y. 1974. Travel-time budgets and mobility in urban areas. Final report. Report FHWA PL-8183. Washington, DC: FHWA, US Department of Transportation.

Zegras, C. 2011. Mainstreaming sustainable urban transport: Putting the pieces together. In H.T. Dimitriou, and R. Gakenheimer (Eds.), Urban transport in the developing world. A handbook of policy and practice (pp.548-588). Northampton, MA: Edward Elgar Publishers. 